\title{
Fenomenología del accidente ofídico: El significado de los daños físicos para la víctima
}

\author{
Dennis Guerra-Centeno \\ msc.dennisguerra@gmail.com \\ Director del Instituto de Investigación en Ciencia Animal y Ecosalud, \\ Facultad de Medicina Veterinaria y Zootecnia \\ Universidad de San Carlos de Guatemala.
}

Fecha de recepción: 27/11/2017

Fecha de aceptación: 22/02/2018

\section{Resumen}

Con el objetivo de mejorar la comprensión del accidente ofídico se investigó el significado que tienen los daños físicos para los sujetos que lo padecen. La descripción se construyó a partir del estudio fenomenológico de víctimas de accidente ofídico de dos comunidades del norte de Guatemala y de la participación de un comercializador de sueros antiofídicos. Este estudio ideográfico se circunscribe a los accidentes sucedidos por víboras pues los ocurridos por corales y serpientes marinas son de baja incidencia en Centroamérica (Bolaños, 1982). Se presenta, también, un esquema que muestra la visión gestáltica de la experiencia física del accidente ofídico.

\section{Palabras clave}

Investigación cualitativa, ofidismo, envenenamiento ofídico, epidemiología social, enfermedad desatendida.

\begin{abstract}
The physical experience of snake bite envenoming - from the moment the victim is bitten to the moment it is discharged from the hospital - is described. The description is constructed from the phenomenological study of 10 snake bite victims from two communities from northern Guatemala and one distributor of antivenoms. The description refers exclusively to snakebite envenomation caused by viper snakes since those caused by coral snakes and marine snakes are extremely rare in Central America (Bolaños, 1982). A diagram showing the gestalt view of the physical experience of snake bite envenoming is also presented.
\end{abstract}

\section{Keywords}

Qualitative research, ophidism, social epidemiology, neglected disease. 


\section{Introducción}

El accidente ofídico ha sido tradicionalmente abordado desde la perspectiva del positivismo. Por lo tanto, los estudios publicados suelen mostrar datos epidemiológicos como la prevalencia, la incidencia o la distribución geográfica de los casos. Algunos estudios han evaluado los rasgos ocupacionales de las personas afectadas y las condiciones en que ocurre el accidente (Guerra-Centeno, 2017a). Este enfoque positivista se ha centrado, sin embargo, en el estudio de los rasgos objetivos del accidente ofídico y ha dejado de lado el estudio de los rasgos subjetivos para la persona que es víctima de esta enfermedad (el sujeto). La información publicada sobre la subjetividad relacionada con el accidente ofídico es, por lo tanto, escasa.

El presente estudio es parte de una investigación de tesis doctoral titulada "Epidemiología social del accidente ofídico en Guatemala: hacia la comprensión de una enfermedad desatendida" y tuvo como propósito la comprensión de los significados de la experiencia física del accidente ofídico desde la perspectiva de las víctimas y de otras personas que viven de cerca este fenómeno. Se espera que la descripción de la subjetividad de este aspecto del accidente ofídico, contribuya a la comprensión de la realidad multidimensional de esta enfermedad.

\section{Metodología}

\subsection{Consideraciones generales}

Como cualquier otra enfermedad, el accidente ofídico se presenta como un fenómeno ante quienes lo padecen y ante los cuales se ven, de alguna manera, afectados o involucrados. En ese sentido, la investigación se desarrolló en el marco del paradigma constructivista y la fenomenología se escogió como la opción metodológica idónea para abordar la investigación. En este estudio, se privilegió la descripción eidética husserliana sobre la descripción ontológica heideggeriana (Ray, 2003; Cohen \& Omery, 2003). El carácter diáfano de los discursos de los campesinos y del resto de los participantes en la investigación permite asomarse a la subjetividad en relación al fenómeno del accidente ofídico y resta importancia a las interpretaciones hermenéuticas innecesarias. En tal sentido, los resultados se presentan de manera descriptiva aunque con algunos segmentos interpretativos y sintéticos.

\subsection{Técnica}

La técnica utilizada fue la entrevista a profundidad centrada en víctimas de accidente ofídico. Para el efecto, se entrevistó a 10 víctimas de esa enfermedad. Estos participantes eran comunitarios de las aldeas El Caoba y San Andrés, en Petén. Adicionalmente se entrevistó a un comercializador de sueros antiofídicos. Para mantener en secreto la identidad de los participantes, los nombres se codificaron como se muestra en la Tabla 1.

Tabla 1

Descripción y código de los participantes

\begin{tabular}{lc}
\hline \multicolumn{1}{|l}{ Tipo de participante } & Código \\
\hline Víctima de accidente ofídico & $\mathrm{V}$ \\
$\begin{array}{l}\text { Comercializador de sueros } \\
\text { antiofídicos }\end{array}$ & CSAO \\
\hline
\end{tabular}

Fuente: Elaboración propia

\subsection{Registro de los datos}

Todas las entrevistas fueron grabadas por duplicado, utilizando una grabadora de audio Tascam DR-07MKII® y una computadora portátil Acer Aspire OneD255E $®$ y fueron transcritas mediante un procesador de textos. El análisis de las transcripciones de las entrevistas fue asistido por el programa QDA Miner Lite ${ }^{\circledR}$. 


\subsection{Consideraciones éticas}

Se obtuvo consentimiento informado de los participantes víctima de accidente ofídico y consentimiento oral del participante comercializador de sueros antiofídicos. Las fotografías fueron tomadas u obtenidas después de la autorización de las personas víctimas de accidente ofídico.

\section{Resultados y discusión}

\subsection{Efectos generales}

La experiencia física y la forma en que se relata, es parte de la subjetividad de la persona y de una comunidad. La cualidad de las respuestas a los estímulos, tanto internos como externos, es susceptible de variar entre una persona y otra. Es interesante, entonces, que las descripciones de los efectos físicos de los venenos de las serpientes narradas por las víctimas hayan sido consistentes. Se captó, por lo tanto, el sentido común derivado de la experiencia del accidente ofídico.

Según la gravedad del accidente ofídico, las víctimas experimentaron síntomas y signos correspondientes a dolor intenso, vista nublada, mareo, desmayo, hemorragias e hinchazón del miembro afectado, dolor de cabeza, sangrado de encías, vómitos con sangre, trastorno funcional del miembro, hemorragia nasal y ocular, orina con sangre, necrosis del miembro afectado, áreas cruentas, fasciotomías y amputación. A medida que los venenos de las víboras se diseminan, estos producen alteraciones que se van sumando (Gutiérrez, 2010). Los daños, que son galopantes, solamente se detienen si la persona logra llegar a un centro asistencial que tenga la capacidad de aplicar suficientes dosis del único tratamiento efectivo, el suero antiofídico (Gutiérrez et al., 2017).

\subsection{Efectos inmediatos}

La primera sensación que manifestaron experimentar las víctimas fue un pinchazo. Este corresponde al momento en que los colmillos de la serpiente perfo- ran la piel. La acción de los colmillos es equivalente al de agujas hipodérmicas que inyectan el veneno dentro de los tejidos (Weinstein, Smith \& Kardong, 2010). Una vez inoculado el veneno, las víctimas sintieron sus dramáticos y letales efectos.

A medida que el veneno se difunde en los tejidos, se produce una sensación de ardor y dolor. El dolor es un rasgo derivado de la subjetivación de los estímulos internos y externos. En el caso del accidente ofídico, hablamos de la subjetivación de los estímulos provocados, primero, por los componentes de los venenos $y$, segundo, por los daños causados por estos. En tal sentido, se consideró el dolor como parte de la experiencia física del accidente ofídico pues es derivado de estímulos físicos.

El participante V5 narra lo que sintió cuando fue mordido: "Entonces, yo lo que sentí fue como cuando se quema con un tizón. Ajá, igual, igual cuando se topa la mano con un tizón igual sentí pero de aquí p'allá ya no sentí nada. Al mismo tiempo yo pensé: no me voy a hacer nada, no va a pasar nada pero, como a los... aproximadamente cinco minutos, comencé a sentir aquí algo como corriendo el veneno en la mano. Entonces lo que yo hice fue amarrarme con una pita pero no fue suficiente... entonces... yo sentí que iba corriendo el veneno... así como algo como fuego, algo asi".

El dolor se intensifica a medida que el veneno avanza en los tejidos del miembro afectado. El participante V1 recuerda: "Llevaba un galón de agua cuando sentí la mordedura, creyendo que era una mordedura de alacrán. Sí pero... en cuanto más pasaba un minuto, dos minutos y... más dolor y más dolor y... en cuanto el alacrán no es igual pues. El alacrán desde el golpe que da... ahí se queda ese dolor y... en cuanto el tiempo va pasando igual se le va mermando el dolor a uno. Lo que es con la barba amarilla que ese fue la clase de culebra que me mordió este... en cuanto pasa el tiempo es más dolor y más dolor y más dolor". El participante V10 narra el dolor que sintió: "No podía caminar... nada, enteramente. Con muletas así caminaba... una muleta de cada lado porque las piernas las tenía bien hinchadas... y aquel dolor... y antes, cuando me mordió, que me acababa de morder... jun 
dolor!... un dolor que no se me quitaba aunque me pusieron el suero. ¡Dolor grave, grave dolor, dolor como cuando uno se está quemando vivo!..".

Los venenos de serpiente, son cócteles de componentes bioactivos cuya función principal es la de inmovilizar y digerir a las presas (Dhananjaya, Vishwanath \& D'Souza, 2010). Es decir, el veneno está diseñado evolutivamente para causar daño y trastorno funcional en el organismo que lo recibe. Como si se tratase de una presa, la inoculación del veneno en una persona, genera los mismos efectos: Los tejidos son dañados progresivamente hasta que dejan de funcionar a medida que son alterados y digeridos.

Después del ardor y de la sensación de quemazón del miembro afectado por la inoculación de veneno, sobreviene el trastorno funcional. Refiere la participante V3: ". . y entonces me fue subiendo un dolor y ya cuando llegué al hospital ya no podía pararme en... así, hacerle fuerza a la canilla verdad". Este trastorno funcional del miembro afectado puede ser dramático cuando la persona se encuentra en la montaña, lejos de los centros de asistencia médica. El participante V6 cuenta su experiencia: "Yo... yo quise caminar. Sólo caminé como 10 metros... como ocho metros tal vez... y se me encogió la canilla va. Y cuando los compañeros llegaron me dicen: ¿dónde te mordió?... Me mordió la canilla muchá. ¿Y dónde está?... allí está, búsquenla. Y se fueron a buscarla y la mataron pues y... viene y uno se fue al campamento. Estábamos como a tres kilómetros del campamento, buscando para un sitio que se llama El Quinal. Y se queda uno cuidándome y me dice: mira...tú estás bien grave, te tenés que entregar a Dios porque a saber qué vaya a pasar contigo, te estás desfigurando la cara... Y le digo: hínqueseme allí y me lleva cargado. Me le tiré encima, lo agarré del cuello y él me pone las manos en el tronco de la pierna. Yo no aguanto [dijo]... y me caminó un poco y me dejó caer. Y con el dolor que llevaba y que el pie lo tenía así encogido...".

El dolor en el miembro afectado persiste mientras aparecen los mareos, la vista nublada y el dolor de cabeza. La participante V4 refiere su experiencia cuando fue mordida: "Me tronó el hueso. Ah ya fue aquella cosa que zumba la cabeza mire. De una vez se va el veneno para la cabeza fíjese. Ah pues... jun hueso me metí! Dije yo. Y aquella cosa quema que quema. Y aquella cosa entre dormido y dolor. Como tres cosas sentía yo...". Por su parte, la participante V2 manifiesta: "pero a todo esto yo tenía un fuerte dolor de cabeza, pero fuerte dolor, que nunca en la vida lo había sufrido. Entonces me echaron a un carro y me llevaron al hospital".

Algunos se desmayan a los pocos minutos de ocurrido el accidente. El participante V7 refiere: "Me hacía el fuerte... pero cuando caminé, a los treinta metros, haciéndome el fuerte... me cayó una nublazón en el cuerpo. Al no más de la mordedura, me empezó a salir sangre demasiado porque me agarró la... me agarró una vena. Me agarró una vena de aquí [el participante se señala una mano]. Pero luego yo, que no quería darles a conocer a mi familia, empecé a caminar. Pero cuando yo me agaché a agarrar un poco de elotes, se me nubló la vista... y me da una bolencia tremenda. Y yo caminaba y caminaba y... después me desmayé como a los... cien metros de caminar me desmayé. Caí, pero me volví a levantar porque no estaba inconsciente. Caminé otros cien metros. Llegué a donde estaba un... el microbús que yo tenía. Me... me aguadé, caí aguado y mi esposa me quiso echar agua. Y de ahí desperté y ella me dijo: tomá agua... pero como yo había trabajado en la policía, cuando a uno lo balean o le pasa algo, no hay que tomar agua... porque si el mordido de serpiente toma agua en el instante, es posible que fallezca porque el agua hacer correr más rápido al corazón". Por su parte, el participante V9 recuerda: "Pero... a la mordida yo sentí luego que se me oscureció la vista, me salió un olor a sangre y ya no pude hacer nada. Estuve como tres horas malo, que no podía mirar".

\subsection{Efectos mediatos}

Las siguientes alteraciones dentro de la experiencia física para las víctimas, suelen ser las hemorragias. La más común según narraron los participantes, es la de las encías. También son frecuentes las hemorragias de ojos, nariz y oídos. Hay que considerar que la experiencia física es acumulativa, lo que puede 
llegar a ser abrumador para la víctima. El participante V7 refiere: "yo sentía que mi mano la agarraban con un leño así [el participante hace ademán como si se pegase en la mano con un leño]. Uno, cuando tiene un golpe, hala aire profundo para volver a [el participante tartamudea y no puede concluir la idea]... pero ahí ya no podía yo, ya no alcanzaba porque yo sentía que era el dolor tremendo. Y me fui poniendo tan... tan hinchado, que ya no. Ya a las once de la noche ya... ya no aguantaba ahí. Eché sangre por las encías y por, por aquí por la esquina de los ojos. Y en el orín... echaba sangre..."

Las hemorragias también ocurren en el miembro afectado según la Figura 1 y son el resultado del daño causado por las enzimas denominadas metaloproteinasas contenidas en los venenos de las víboras (Jia, Shimokawa, Bjamason \& Fox, 1996).

\section{Figura 1}

Hemorragias en pierna de niña por mordedura de una barba amarilla (Bothrops asper).

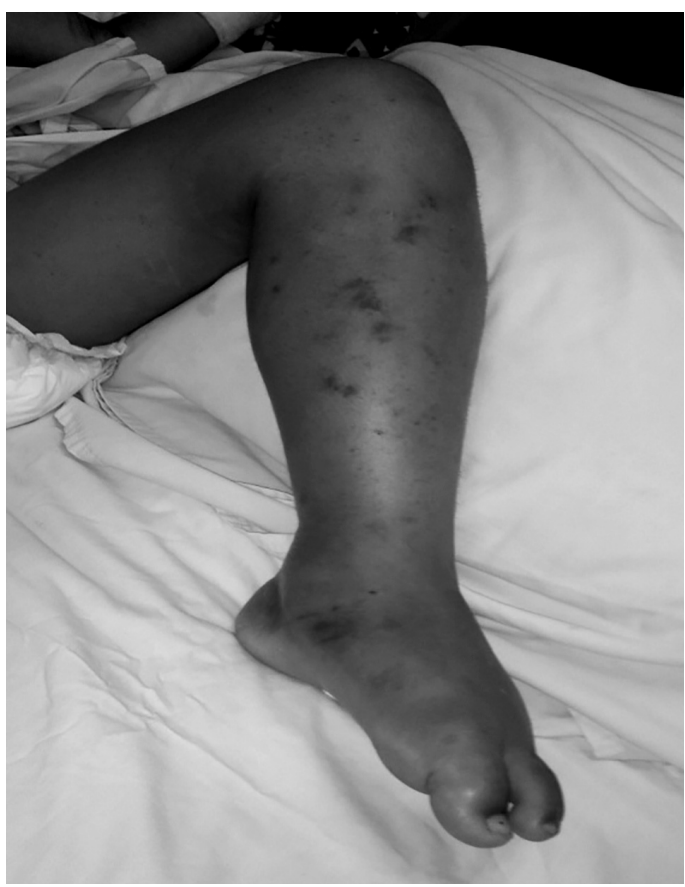

Fuente: Hospital de San Benito, Petén (2013). Niña de siete años que refirió haber sido mordida en su casa por una barba amarilla (Bothrops asper). Fotografía tomada con el consentimiento oral del padre de la paciente.
Las ampollas, son causadas también por estas enzimas y son parte de la experiencia física del accidente ofídico como se muestra en la Figura 2.

Figura 2

Ampollas causadas por mordedura de víbora

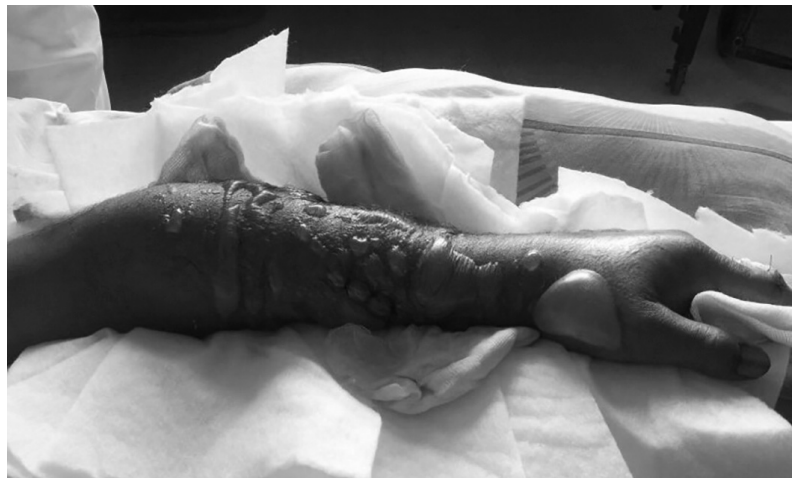

Fuente: Hospital de San Benito, Petén (2013). Fotografía cortesía de Dr. Melvin Vásquez, director del Hospital de San Benito.

\subsection{Efectos posteriores}

A medida que transcurre el tiempo, los efectos del veneno en los tejidos se van adicionando. Son comunes la inflamación, el edema y la necrosis acompañados de mucho dolor. Los daños en el miembro afectado, pueden ser irreversibles, aun cuando se hayan aplicado varias dosis de suero antiofídico. El participante V7 experimentó una serie de cambios que concluyeron en una situación de daño físico permanente. Este participante refiere: "en el intensivo llegué a ponerme tan hinchado que desgraciadamente no hubo quién me tomara una foto... Todo el brazo, de aquí del pecho y la cara. Pero mire usted... yo no sé de dónde dio tanto mi brazo. De ahí, pues estuve tres días en intensivo".

Continúa el participante V7: "De ahí, se reventó toda la piel, y empezó a echar agua amarilla. Pero aquí donde estaba la mordedura [el participante se señala la mano], se amontonó todo y se pudrió todo lo que es la mano. Entonces, la mano me quedó así [el participante tiene la mano atrofiada y no puede estirar los dedos] porque los nervios se 
expusieron. Les pegó aire. Entonces... ya cuando juntó carne... a mí me dijeron que me iban a amputar la mano, pero yo firmé un documento y me vine [egresó del hospital], y dije que tenía fe que me echaba carne y me echó pero me quedó así engarabatada, pero aquí la tengo...".

En casos severos de accidente ofídico, se desencadena un cuadro clínico dramático y nefasto denominado síndrome compartimental. Este síndrome consiste en el aumento de la presión en un espacio o compartimiento osteo-aponeurótico', por arriba de la presión de perfusión, comprometiendo el flujo sanguíneo y la función de tejidos musculares y nervios (Alfaro, 2010). En otras palabras, se acumula líquido en el espacio que hay entre los huesos (como el fémur o el húmero) y las aponeurosis, dificultando la llegada de sangre a los músculos y los nervios del miembro afectado.
Debido a que la disminución en la llegada de sangre (isquemia) puede producir daños irreversibles en el miembro afectado y conducir al cuadro llamado por los médicos "miembro letal" que invariablemente conduce a la amputación, los médicos intentarán resolver la situación antes de llegar a esos extremos. Sin embargo, el tratamiento del síndrome compartimental parece ser más dramático que el cuadro mismo y se denomina fasciotomía (nombre que significa "corte del envoltorio"). Dicho procedimiento consiste en tratar de aliviar la presión disecando (dividiendo) las capas musculares y las fascias, hasta llegar al hueso, dejando el miembro disecado por varios días como se ve en las Figuras 3 y 4 .

Figura 3

Casos de síndrome compartimental

tratados mediante fasciotomía en pacientes de accidente ofídico, atendidos en el Hospital San Carlos, Alajuela, Costa Rica
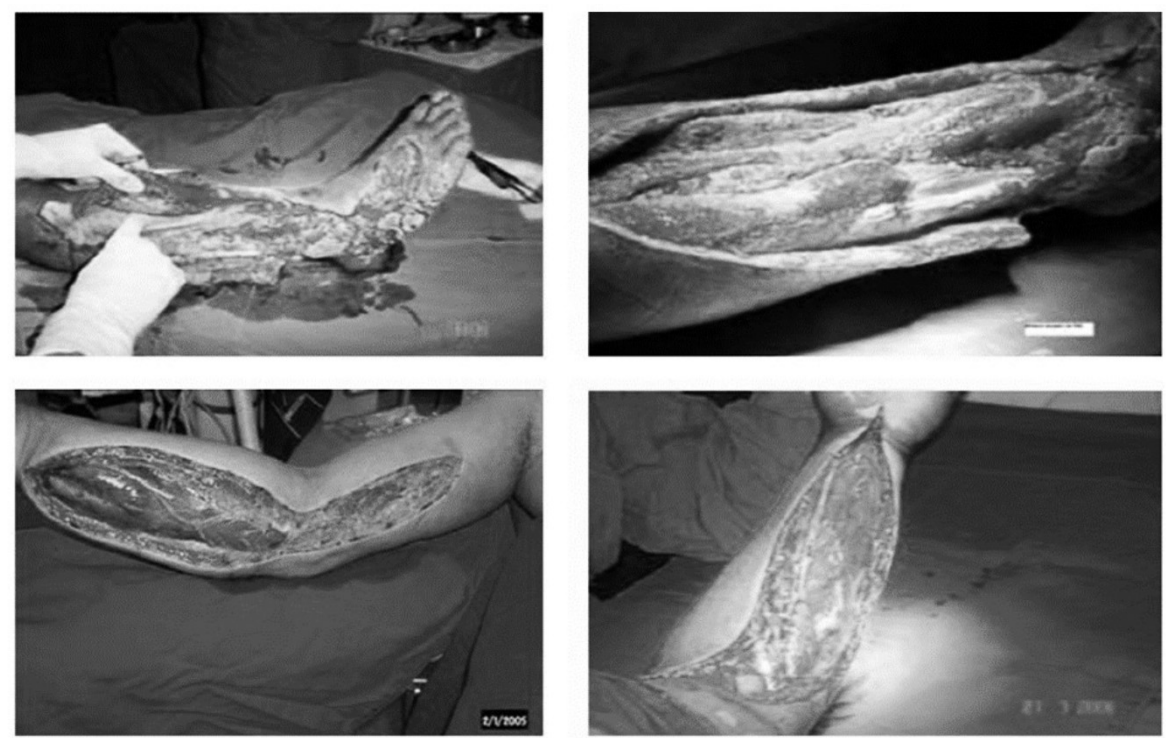

Fuente: Alfaro (2010).

1 El espacio osteo-aponeurótico es el espacio virtual entre un hueso y una aponeurosis -un tipo de tendón con forma de lámina aplanada-. 
Figura 4

Fasciotomía múltiple y debridación de tejido necrótico

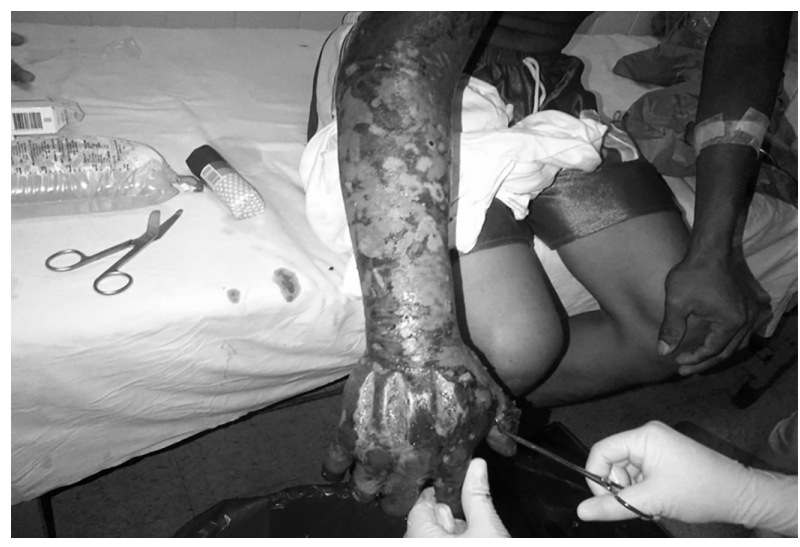

Se observa imagen de un agricultor de 38 años presuntamente mordido por barba amarilla (Bothrops asper), en miembro superior derecho atendido en el Hospital de San Benito.

Fuente: Hospital de San Benito, Petén. Fotografía cortesía de Carlos Llamas, Departamento de Epidemiología, Hospital de San Benito.

Permanecer por varios días con los tejidos internos del miembro afectado expuestos al ambiente, supone en sí mismo un gran riesgo de infecciones. Más aún, permanecer con los tejidos expuestos en un hospital nacional donde las condiciones de asepsia no siempre son las deseables y donde las infecciones por bacterias nosocomiales resistentes a antibióticos son comunes, supone un riesgo mayor (Hernández-Granados \& Arathoon, 1993; Mejía-Villatoro et al., 2008; Seaman, 2011).

La aplicación de varias dosis de suero antiofídico no siempre logra evitar la aparición o la resolución satisfactoria del temido síndrome compartimental. Algunos venenos como el de la serpiente de cascabel (Crotalus simus) producen efectos edematizantes que los antídotos no logran revertir eficientemente (Rojas, et al. 1987). Por tal motivo, los casos de síndrome compartimental son más frecuentes en personas provenientes del sur de Guatemala, donde la serpiente cascabel es más común (Guerra-Centeno, 2017a).
En el área circundante al sitio de la mordedura e inoculación de veneno, los efectos necrotizantes del veneno, a menudo producen áreas cruentas (Figura 5) Estas áreas cruentas, son consecuencia de la muerte y pérdida del tejido y pueden ser la puerta de entrada para infecciones. En algunos casos, aún con el tratamiento hospitalario con sueros antiofídicos, las áreas cruentas conducen a necrosis gangrenosa y a miembro letal. Como se dijo, el miembro letal con gangrena, debe ser amputado para salvaguardar la vida de la persona. Además de la pérdida del miembro afectado y de la disfunción para trabajos físicos como la agricultura, la amputación tiene un efecto psicosocial sobre el sujeto.

\section{Figura 5}

Área cruenta en pie izquierdo de una mujer de 49 años, mordida por una víbora, probablemente de la especie Porthidium nasutum. En este caso se indicó la amputación

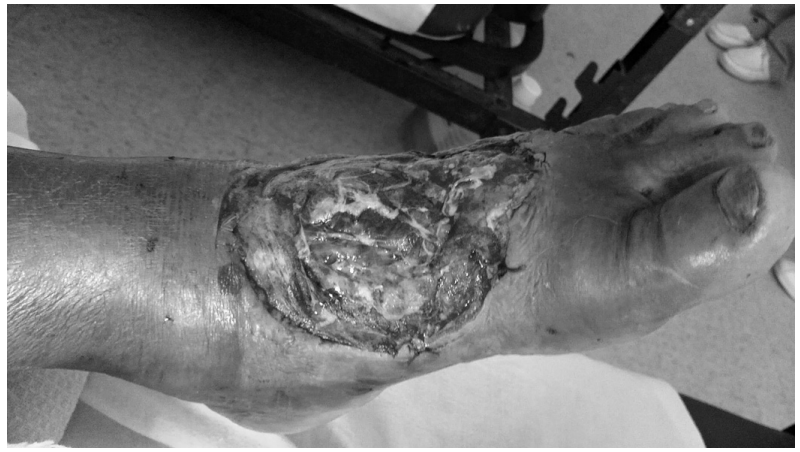

Fuente: Fotografía tomada con el consentimiento oral de la paciente.

\subsection{Efectos permanentes}

La amputación es una consecuencia común del daño físico severo a los tejidos de un miembro. Suele ser el resultado de la aplicación de un torniquete -el cual está contraindicado en los casos de mordedura por víboras cuyo veneno necrosa los tejidos- que hace que la acción del veneno se concentre en una parte relativamente pequeña del cuerpo. Los médicos toman la decisión de amputar un miembro, cuando la necrosis hace peligrar la vida de la persona. 
Después de solicitar por escrito el consentimiento o autorización de la persona, se remueve el miembro afectado. Refiere el participante V8: "A mí, me hicieron cinco operaciones del brazo. La primera fue que se me murieron los tres dedos. Y luego me los amputaron. Después siguió el proceso de las operaciones del brazo que empezó ahí pudriendo. Le cayó gangrena. Y después... llegó el término que llegó el puro hueso descubierto. Después le cayó el tétano. De ahí fue donde me amputaron el brazo. De ahí pues... esto lo que le quiero decir es que fue un proceso como de dos meses. Durante esos dos meses pasé una experiencia mucho más... muy duro. A veces... ni yo mismo me lo puedo explicar. Solamente lo vuelvo a repetir... estoy vivo por la gracia y misericordia de Dios". De ahí en adelante, las capacidades y la vida del sujeto se verán afectadas dramáticamente.

Se ha descrito hasta ahora, la experiencia física del accidente ofídico que culmina con una persona recuperada, aunque sea con secuelas permanentes. Sin embargo, algunos casos terminan con la muerte de la persona. Pero, ¿qué es lo que hace que una persona muera por accidente ofídico? Ya se dijo que los venenos dañan los tejidos a medida que se difunden a través del organismo de la víctima. Cuando este daño alcanza órganos vitales -generalmente por atrasos en la aplicación del suero antiofídico-, sobreviene la muerte. La muerte puede ocurrir por hemorragia -sobre todo cerebral-, choque cardiovascular, infección generalizada, fallo renal agudo o aborto (Gutiérrez, 2010).

Lo más común en Guatemala son los daños a los riñones (Guerra-Centeno, 2017b), y esto es más frecuente en niños cuya masa corporal es propor- cionalmente más pequeña que la de un adulto. Refiere el participante CSAO: "En el hospital de Cuilapa, hubo un fallecimiento de un niño con suero nuestro. Y entonces, mi socio, echó viaje para ver la ficha, la ficha médica. Y le informaron de que como era tan chiquitín, nada más le habían administrado la mitad de la dosis. Entonces, mi socio les explicó que la serpiente, si va a morder a un cebú o va a morder a un elefante o va a morder a un caballo, la dosis líquida de veneno que suelta, es la misma". En estos casos los venenos generan daños masivos, incluyendo una insuficiencia renal aguda que conduce a la muerte. En casos menos frecuentes, el veneno puede dañar la musculatura del corazón, causando un paro cardíaco (Hardy, 1986) o el tejido encefálico causando un choque cerebral (Mosquera, Idrovo, Tafur \& Del Brutto, 2003).

En síntesis, la experiencia física del accidente ofídico consiste en una progresión de alteraciones y daños a los tejidos (Figura 6). La experiencia suele empezar con dolor del sitio de la mordedura, mareos, vista nublada, dolor de cabeza, hemorragias de encías, nariz, ojos, oídos y miembro afectado, desmayos, hinchazón del miembro afectado e imposibilidad de moverlo. Si la persona logra llegar a un centro asistencial que cuente con suficientes dosis del antídoto adecuado, le aplicarán el tratamiento que pretende frenar el avance de los daños. En este momento, el cuadro puede evolucionar de dos formas: (1) remisión de los daños, (2) avance de los daños hasta una rabdomiólisis y síndrome compartimental o hasta la amputación del miembro afectado o la muerte de la persona. La evolución de la experiencia física del accidente ofídico, desde la perspectiva de la víctima se puede observar en la Figura 6. 
Figura 6

\section{Evolución de la experiencia física del accidente ofídico, desde la perspectiva de la víctima}

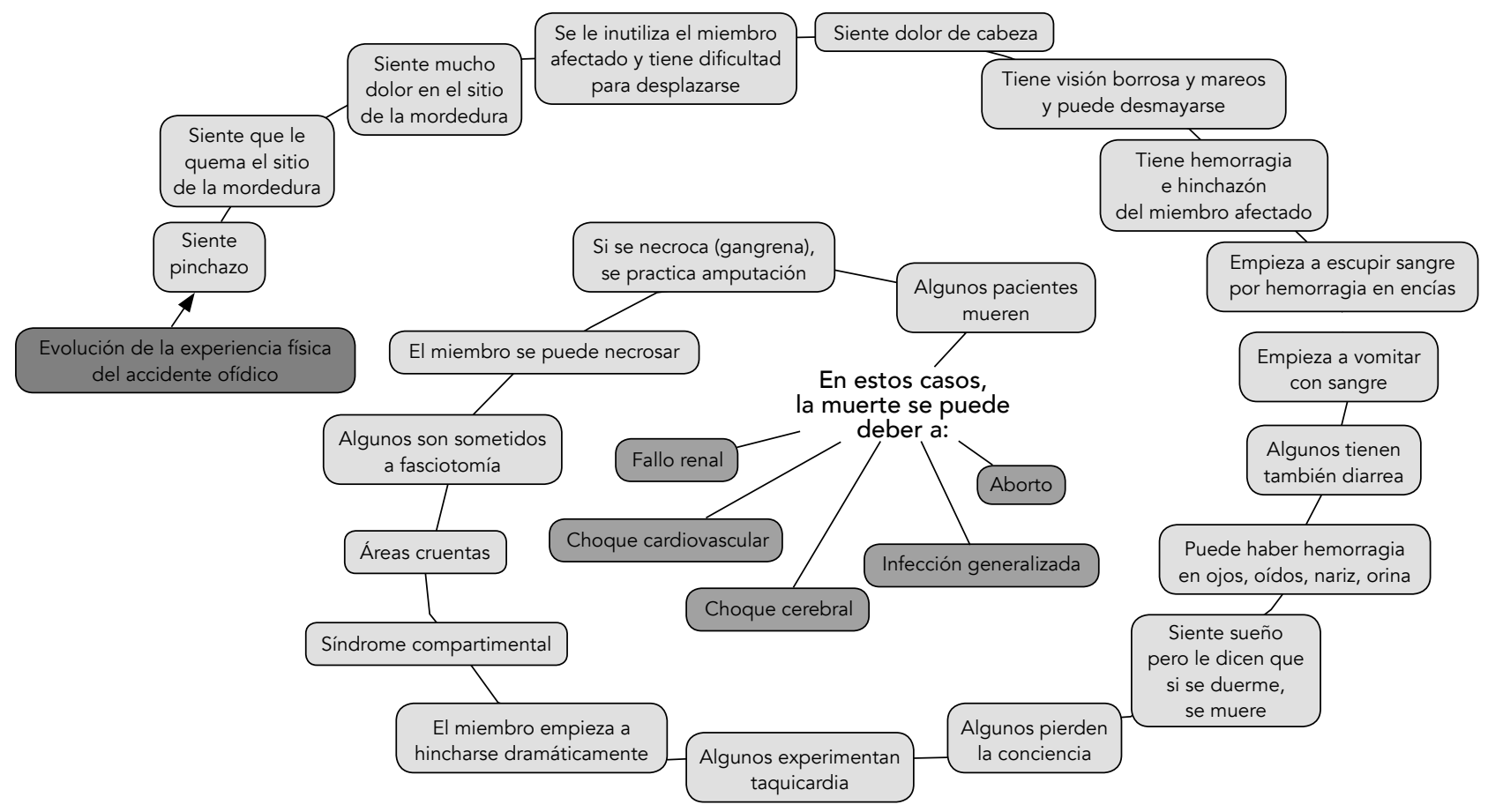

Fuente: Elaboración propia

\section{Conclusión}

El conjunto de eventos y de alteraciones físicas que suceden durante el accidente ofídico y la forma en que van ocurriendo, impactan al sujeto profundamente y generan significados de dolor, miedo, ansiedad y, sobre todo, posibilidad de morir, con las consecuencias que esto tiene para el sostenimiento de la familia. La elocuencia que se percibe de inmediato en las narraciones de las víctimas, es indicio de lo anterior. Desde una perspectiva evolucionista, este impacto profundo tiene un objetivo: que el individuo pueda hacer los ajustes necesarios para disminuir la probabilidad de ser mordido y envenenado nuevamente. Es lógico pensar que la fuerte experiencia física vaya acompañada de una, también fuerte, experiencia psíquica sobre todo, considerando que el campesino guatemalteco es vulnerable al accidente ofídico de manera multidimensional (Guerra-Centeno, 2017b).
El estudio de la experiencia física del accidente ofídico desde la perspectiva de la víctima y de los que lo viven de cerca, mediante métodos cualitativos, puede contribuir significativamente en nuestro entendimiento y comprensión de este fenómeno. Basándonos en la premisa de que no se pueden atender los problemas que no se comprenden, podríamos suponer que la comprensión de los significados multidimensionales del accidente ofídico para los involucrados, tendría un efecto positivo en la prevención del riesgo, la mitigación de la vulnerabilidad y la preparación para afrontar los casos de esta enfermedad.

\section{Agradecimientos}

Se agradece a los participantes en el presente estudio, así como a Rony García Anleu y a Marcial Córdova de Wildlife Conservation Society por el apoyo en el transporte, hospedaje y logística de campo en Petén, Guatemala. 


\section{Referencias}

Alfaro, E. (2010). Síndrome compartimental por envenenamiento ofídico. (Manejo de fasciotomía con terapia VAC). Revista Médica de Costa Rica y Centroamérica 594, 405-415.

Bolaños, R. (1982). Las serpientes venenosas de Centroamérica y el problema del ofidismo. Primera parte. Aspectos zoológicos, epidemiológicos y biomédicos. Revista Costarricense de Ciencias Médicas, 3(2), 165-184.

Cohen, M. Z. \& Omery, A. (2003). Escuelas de fenomenología: implicaciones para la investigación. En Janice Morse, (Ed.). Asuntos críticos en los métodos de investigación cualitativa (pp. 160-182). Antioquia: Editorial Universidad de Antioquia.

Dhananjaya, B., Vishwanath, B. y D'Souza, C. (2010). Snake Venom Nucleases, Nucleotidases, and Phosphomonoesterases, pp. 155-171. En: Mackessy S. (Ed.) Handbook of Venoms and Toxins of Reptiles. Boca Raton: CRC Press.

Guerra-Centeno, D. (2017a). Perfil epidemiológico del accidente ofídico en las tierras bajas de Guatemala. Ciencia, Tecnología y Salud, 3(2), 127-138.

Guerra-Centeno, D. (2017b). La vulnerabilidad multidimensional del campesino guatemalteco al accidente ofídico. REDVET. Revista Electrónica de Veterinaria, 18(9), 1-25.

Gutiérrez, J. (2010). Snakebite Envenomation in Central America. En S. Mackessy (Edit.), Handbook of venoms and toxins (pp. 491-507). Boca Raton: CRC Press.

Gutiérrez, J. M., Solano, G., Pla, D., Herrera, M., Segura, Á., Vargas, M., ... \& León, G. (2017). Preclinical evaluation of the efficacy of antivenoms for snakebite envenoming: State-of-theart and challenges ahead. Toxins, 9(5), 163.
Hardy, D. L. (1986). Fatal rattlesnake envenomation in Arizona: 1969-1984. Journal of Toxicology: Clinical Toxicology, 24(1), 1-10.

Hernández-Granados, J., \& Arathoon, E. (1993). Resistencia bacteriana en gérmenes nosocomiales en el Hospital General San Juan de Dios, Guatemala. Revista de Medicina Interna, 4(1), 2-11.

Jia, L. G., Shimokawa, K. I., Bjarnason, J. B., \& Fox, J. W. (1996). Snake venom metalloproteinases: structure, function and relationship to the ADAMs family of proteins. Toxicon, 34(11), 1269-1276.

Mejía Villatoro, C., Villatoro Nazareno, G., Silvestre, M., De Briz, H., Valle, R., \& Gordillo, M. (2008). Costo del tratamiento de infecciones nosocomiales por gérmenes multirresistentes, Hospital Roosevelt, Guatemala. Revista del Colegio de Médicos y Cirujanos de Guatemala, (2), 36-39.

Mosquera, A., Idrovo, L. A., Tafur, A., \& Del Brutto, O. H. (2003). Stroke following Bothrops spp. snakebite. Neurology, 60(10), 1577-1580.

Seaman, I. (2011). Costo social de las infecciones nosocomiales. Revista de Medicina de Honduras, 79(3), 155-60.

Ray, M. (2003). La riqueza de la fenomenología: preocupaciones filosóficas, teóricas y metodológicas. En Janice Morse, (Ed.). Asuntos críticos en los métodos de investigación cualitativa (pp. 139-157). Antioquia: Editorial Universidad de Antioquia.

Rojas, G., Gutiérrez, J., Gené, J., Gómez, M., \& Cerdas, L. (1987). Neutralización de las actividades tóxicas y enzimáticas de cuatro venenos de serpientes de Guatemala y Honduras por el antiveneno polivalente producido en Costa Rica. Revista de Biología Tropical, 35(1), 59-67.

Weinstein, S. A., Smith, T. L., \& Kardong, K. V. (2010). Reptile Venom Glands: Form, function, and future. En S. Mackessy (Edit.), Handbook of venoms and toxins (pp. 65-91). Boca Raton: CRC Press. 